\title{
Analysis on genetic diversification and heterosis in autotetraploid rice
}

\author{
Jin-Wen Wu ${ }^{\dagger}$, Chao-Yue Hu${ }^{\dagger}$, Muhammad Qasim Shahid ${ }^{\dagger}$, Hai-Bin Guo, Yu-Xiang Zeng, Xiang-Dong Liu* \\ and Yong-Gen Lu*
}

\begin{abstract}
Polyploidization has played an important role in plant evolution and is a pathway for plants to increase genetic diversification and to get higher heterosis comparing with that of diploid does. This study was undertaken to assess the genetic variation and relationships among 40 autotetraploid rice genotypes and their counterpart diploid cultivars with 99 SSR markers screened from published rice genome. The 99 SSR markers detected polymorphism among autotetraploid genotypes and revealed a total of 291 alleles with an average of 2.949 alleles per locus. Autotetraploid lines showed higher genetic diversity and significant variation in agronomic traits than diploid cultivars. Phylogenetic analysis revealed that most of autotetraploid lines were genetically different from their diploid parents, and inter-subspecific hybrids were prepared on the basis of genetic distance between parents. Inter-subspecific autotetraploid hybrids showed a higher and positive heterobeltiosis and competitive heterosis than diploid hybrids, especially for grain yield. Genetic distance appeared not to predict heterosis in diploid rice for all traits; however, it showed a significant correlation with grain yield, grain length and grain length to width ratio in autotetraploid rice. This extensive research on autotetraploid heterosis and genetic diversity will be useful for the development of autotetraploid rice hybrids.
\end{abstract}

Keywords: Genetic distance; Genetic variation; Heterobeltiosis; Inter-subspecific hybrids; Polyploidy

\section{Introduction}

Polyploidization has played an important role in plant evolution and is a pathway for plants to increase genetic diversification and to get higher heterosis comparing with that of diploid does (Doyle et al. 2008; Luan et al. 2008; Shahid et al. 2012). Over $70 \%$ of all angiosperm species have an increase in ploidy level somewhere during their evolutionary histories (Masterson 1994). Polyploid species with doubling genomes showed abundant advantages for various traits, such as greater variation, high biomass yield and resistance to insect pest and diseases (Bingham et al. 1994; Marhold and Lihová 2006).

Autotetraploid rice is a new germplasm developed from diploid rice through chromosome doubling with colchicine treatment and has the potential to increase rice production and nutrition (Song and Zhang 1992; Shahid et al. 2012). Autotetraploid lines showed significantly lower fertility

\footnotetext{
* Correspondence: xdliu@scau.edu.cn; yglu@scau.edu.cn

${ }^{\dagger}$ Equal contributors

State Key Laboratory for Conservation and Utilization of Subtropical Agrobioresources, South China Agricultural University, Guangzhou 510642, China
}

than diploid cultivars (Shahid et al. 2010), but autotetraploid hybrids produced significantly higher fertility than their diploid counterparts (Hu et al. 2009; Shahid et al. 2011). Autotetraploid rice showed higher genetic variation in various agronomic traits than their original diploid rice, such as varying seed set along with longer grains and awns (Li and Rutger 2007; Luan et al. 2008). Inter-subspecific (indica $\times$ japonica) autotetraploid rice hybrids showed more hybrid vigour and stability than diploid hybrids, although a lower seed set is a hindrance in heterosis utilization (Shahid et al. 2011). Autotetraploid rice germplasm for hybrid rice application, including genetic variation and diversity, has not been exploited. Therefore, it is of immense importance to study the genetic variation and to utilize the super heterosis of autotetraploid rice.

Heterosis or hybrid vigor is an important tool for improving the quality and increasing yield of crops since its success in maize. Hybrid breeding has been an important method of increasing grain yield of rice and inter-subspecific crosses, such as indica and japonica, showed a great potential to raise grain yield than other

\section{实}

(c) 2013 Wu et al.; licensee Springer. This is an Open Access article distributed under the terms of the Creative Commons Attribution License (http://creativecommons.org/licenses/by/2.0), which permits unrestricted use, distribution, and reproduction in any medium, provided the original work is properly cited. 
crosses (Yuan 1987). Most of super rice breeding programs in China have used inter-subspecies heterosis (Cheng et al. 2007). However, the use of heterosis is extremely labour intensive, time consuming, tedious and required a large number of cross-combinations (Zha et al. 2008). The use of molecular markers for prediction of heterosis led into a new phase since its appearance in 1980 (Xiao et al. 1996). A number of studies have been made in various crop plants to predict the relationship between genetic diversity and heterosis, such as diploid rice (Xiao et al. 1995; Zhao et al. 1999; Wang et al. 2013), wheat (Martin et al. 1995), maize (Smith et al. 1990; Betran et al. 2003), barley (Schut et al. 1997) and rape seed (Liu et al. 2002; Yu et al. 2005). Unfortunately, these studies showed two different and contradictory results, some revealed that markers could be used for predicting heterosis, while some other proposed markers could not predict heterosis for complicated traits.

Molecular markers are a powerful tool for the assessment of genetic variability and genetic diversity among genotypes within land races, populations and species. Among PCR-based markers, SSR markers are the most favored in breeding and genetics because of their codominant nature, abundance, genome wide coverage and high reproducibility (McCouch et al. 2002). Molecular markers could be used to select parents for hybridization because of the association with different alleles and heterosis (Anand et al. 2012). A number of efforts have been made to investigate the genetic variation of the hybrid parents and heterosis in diploid rice. To the best of our knowledge, there is no report on the relationship of molecular markers genetic distance with hybrid performance in autotetraploid rice. However, there is relatively little known about the detection of genetic variation through SSR markers in autotetraploid rice, which limited the cognition of autotetraploid germplasm in the development of hybrid rice. The objectives of this study were (1) to analyze the genetic variation and genetic distance of autotetraploid and diploid rice using SSR markers, and its relation with heterosis prediction (2) to examine genetic relationship of autotetraploid and corresponding diploid rice cultivars, and (3) to investigate the heterosis of yield and important agronomic traits among autotetraploid and corresponding diploid rice cultivars.

\section{Materials and methods Plant materials}

A total of forty autotetraploid rice lines were used to conduct the study about genetic variation, and their 40 diploid parents were used as control (CK) (Table 1). All materials were planted at the experimental farm of South China Agricultural University (SCAU). Row to row $(\mathrm{R} \times \mathrm{R})$ and plant to plant $(\mathrm{P} \times \mathrm{P})$ distances were kept as $20 \mathrm{~cm}$ and $16.6 \mathrm{~cm}$, respectively. In addition, four japonica and seven indica autotetraploid rice lines with high genetic diversity were selected based on the results of phylogenetic analysis (Table 2), and then crossed in an incomplete diallel design during 2010. A total of 54 inter-subspecific hybrids (indica $\times$ japonica) of autotetraploid and their counterpart diploid rice were prepared to determine the relationship between hybrid performance and genetic distance. Parents and $F_{1}$ hybrids were planted at the farm of SCAU to conduct the study for heterosis analysis. A Randomized Complete Block Design (RCBD) was used with three replications. $\mathrm{R} \times \mathrm{R}$ and $\mathrm{P} \times \mathrm{P}$ distances were kept as 20 and $16.6 \mathrm{~cm}$, respectively. Seedlings at four-five leaf stage were planted in the paddy field. The $\mathrm{F}_{1}$ seeds were harvested from all the crosses at the end of cropping season. All the cultural practices were done according to the recommendations of area.

\section{Analysis of agronomic traits}

A total of 14 agronomic traits were investigated to find the genetic variation in diploid and autotetraploid rice $i$. e., plant height $(\mathrm{PH}, \mathrm{cm})$, panicle length $(\mathrm{PL}, \mathrm{cm})$, effective panicles number (EPN), flag leave length (FLL, cm), flag leave width (FLW, $\mathrm{cm}$ ), grain length $(\mathrm{GL}, \mathrm{cm})$, grain width $(\mathrm{GW}, \mathrm{cm})$, grain length to width ratio (L/W), grain density (GD), grain yield (GY), grains per panicle (GPP), total number of grains per plant (TGP), 1000grain weight (GWT, g) and seed set ratio ((SS = number of filled grains/total number of grains $) \times 100)$. Autotetraploid and diploid rice hybrids were planted to examine eleven important agronomic traits: PH, PL, EPN, GL, GW, L/W, GPP, GD, GWT, GY and SS. These traits were selected from the Descriptors and Data Standard for Rice (Oryza sativa L.) to describe the genetic variation between autotetraploid and diploid rice cultivars (Han and Wei 2006).

\section{DNA extraction and SSR analysis}

Young leaves were collected from autotetraploid and diploid rice cultivars, and DNA was extracted using modified SDS method (Yang et al. 2009). SSR markers developed by Cornell University and selected from the Gramene database http://www.gramene.org/ were used (Chen et al. 1997; Jaiswal et al. 2006). The volume of the PCR reaction system was $20 \mu \mathrm{L}$. The profile of PCR program was as follows: $94^{\circ} \mathrm{C}$ for $5 \mathrm{~min}$; 30 cycles of $94^{\circ} \mathrm{C}$ for $1 \mathrm{~min}, 55^{\circ} \mathrm{C}$ for $1 \mathrm{~min}, 72^{\circ} \mathrm{C}$ for $1 \mathrm{~min}$; and $5 \mathrm{~min}$ final extension at $72^{\circ} \mathrm{C}$. All amplified products were separated by $6 \%$ polyacrylamide gel electrophoresis and detected by silver nitrate staining. Alleles were mainly detected by BIO Imagine System and software Genetools from SynGene and manually re-checked twice. 
Table 1 Name of the cultivars with ploidy levels used in this study

\begin{tabular}{|c|c|c|c|c|c|c|c|}
\hline Code & Cultivar & Ploidy & Origion/source & Code & Cultivar & Ploidy & Origion/source \\
\hline 1 & Aijiaonante & $2 x$ & Guangdong & 41 & $\mathrm{Bo}^{\prime} \mathrm{B}$ & $2 x$ & Guangxi \\
\hline 2 & Aijiaonante & $4 \times$ & $\operatorname{Lab}^{a}$ & 42 & Bo'B & $4 \times$ & Lab \\
\hline 3 & Guanglu'ai 4 & $2 x$ & Guangdong & 43 & Taichung 65 & $2 x$ & Taiwan \\
\hline 4 & Guanglu'ai 4 & $4 \times$ & Lab & 44 & Taichung 65 & $4 \times$ & Lab \\
\hline 5 & L-202 & $2 x$ & $|R R|^{b}$ & 45 & E2 & $2 x$ & Guangdong \\
\hline 6 & L-202 & $4 \times$ & SCBG- CAS $^{C}$ & 46 & E2 & $4 \times$ & Lab \\
\hline 7 & Jackson & $2 x$ & IRRI & 47 & E4 & $2 x$ & Guangdong \\
\hline 8 & Jackson & $4 \times$ & SCBG-CAS & 48 & E4 & $4 \times$ & Lab \\
\hline 9 & PEDR-2B & $2 x$ & Guangdong & 49 & E5 & $2 x$ & Guangdong \\
\hline 10 & PEDR-2B & $4 \times$ & Lab & 50 & E5 & $4 \times$ & Lab \\
\hline 11 & Liaojing 944 & $2 x$ & Liaoning & 51 & E24 & $2 x$ & Guangdong \\
\hline 12 & Liaojing 944 & $4 \times$ & Lab & 52 & E24 & $4 \times$ & Lab \\
\hline 13 & Yanjing 48 & $2 x$ & Liaoning & 53 & E45 & $2 x$ & Guangdong \\
\hline 14 & Yanjing 48 & $4 \times$ & Lab & 54 & E45 & $4 \times$ & Lab \\
\hline 15 & Bengal & $2 x$ & IRRI & 55 & E245 & $2 x$ & Guangdong \\
\hline 16 & Bengal & $4 \times$ & Lab & 56 & E245 & $4 x$ & Lab \\
\hline 17 & Raopingsaozhou & $2 x$ & Guangdong & 57 & Lemont & $2 x$ & |RRI \\
\hline 18 & Raopingsaozhou & $4 \times$ & Lab & 58 & Lemont & $4 \times$ & Lab \\
\hline 19 & $J 455$ & $2 x$ & Guangdong & 59 & APIV & $2 x$ & Lab \\
\hline 20 & $J 455$ & $4 \times$ & Lab & 60 & APIV & $4 \times$ & Lab \\
\hline 21 & Nanhaizaoyinzhan & $2 x$ & Guangdong & 61 & 8821 & $2 x$ & Guangdong \\
\hline 22 & Nanhaizaoyinzhan & $4 \times$ & Lab & 62 & 8821 & $4 \times$ & Lab \\
\hline 23 & Yuhei 1 & $2 x$ & Lab & 63 & M18 & $2 x$ & Guangdong \\
\hline 24 & Yuhei 1 & $4 \times$ & Lab & 64 & M18 & $4 \times$ & Lab \\
\hline 25 & Xichuan & $2 x$ & Guangdong & 65 & 02428 & $2 x$ & Jiangsu \\
\hline 26 & Xichuan & $4 \times$ & Lab & 66 & 02428 & $4 \times$ & Lab \\
\hline 27 & Yuexiangzhan & $2 x$ & Guangdong & 67 & Dalinuo & $2 x$ & Guangdong \\
\hline 28 & Yuexiangzhan & $4 \times$ & Lab & 68 & Dalinuo & $4 \times$ & Lab \\
\hline 29 & Dayebai & $2 x$ & Guangdong & 69 & Huajingxian 74 & $2 x$ & Guangdong \\
\hline 30 & Dayebai & $4 \times$ & Lab & 70 & Huajingxian 74 & $4 \times$ & Lab \\
\hline 31 & Guinongzhan & $2 x$ & Guangdong & 71 & PII-6 & $2 x$ & Lab \\
\hline 32 & Guinongzhan & $4 \times$ & Lab & 72 & PII-6 & $4 \times$ & Lab \\
\hline 33 & Shennong 265 & $2 x$ & Liaoning & 73 & Shuya & $2 x$ & Lab \\
\hline 34 & Shennong 265 & $4 \times$ & Lab & 74 & Shuya & $4 \times$ & Lab \\
\hline 35 & Shennong 15 & $2 x$ & Liaoning & 75 & Nanjing 11 & $2 x$ & Jiangsu \\
\hline 36 & Shennong 15 & $4 \times$ & Lab & 76 & Nanjing 11 & $4 \times$ & Beijing \\
\hline 37 & Goulianzao & $2 x$ & Guangdong & 77 & Nantehao & $2 x$ & Guangdong \\
\hline 38 & Goulianzao & $4 x$ & Lab & 78 & Nantehao & $4 \times$ & Lab \\
\hline 39 & Linglun & $2 x$ & Hunan & 79 & Huayinzhan & $2 x$ & Guangdong \\
\hline 40 & Linglun & $4 \times$ & Lab & 80 & Huayinzhan & $4 \times$ & Lab \\
\hline
\end{tabular}

$2 \times$ indicates diploid rice, $4 \times$ indicates autotetraploid rice.

${ }^{a}$ State Key Laboratory for Conservation and Utilization of Subtropical Agro-bioresources, South China Agricultural University, Guangzhou 510642, China. b International Rice Research Institute.

'South China Botanical Garden, Chinese Academy of Sciences. 
Table 2 Name and types of the parents used to prepare inter-subspecific hybrids

\begin{tabular}{|c|c|c|c|c|c|}
\hline \multirow[t]{2}{*}{ Sr. \# } & \multicolumn{2}{|c|}{ Diploid parents } & \multirow[t]{2}{*}{ Sr. \# } & \multicolumn{2}{|c|}{ Autotetraploid parents } \\
\hline & Name & Type & & Name & Type \\
\hline 1 & Liaojing 944-2x & japonica & 1 & Liaojing 944-4x & japonica \\
\hline 2 & Yanjing 48-2x & japonica & 2 & Yanjing 48-4x & japonica \\
\hline 3 & Shennong $15-2 x$ & japonica & 3 & Shennong $15-4 x$ & japonica \\
\hline 4 & Taichung 65-2x & japonica & 4 & Taichung 65-4x & japonica \\
\hline 5 & Aijiaonante-2x & indica & 5 & Aijiaonante-4x & indica \\
\hline 6 & Guanglu'ai 4-2x & indica & 6 & Guanglu'ai 4-4x & Indica \\
\hline 7 & PDER-2B-2x & indica & 7 & PDER-2B-4x & Indica \\
\hline 8 & Raopingsaozhou-2x & indica & 8 & Raopingsaozhou-4x & indica \\
\hline 9 & Nanhaizaoyinzhan-2x & indica & 9 & Nanhaizaoyinzhan-4x & indica \\
\hline 10 & Xichuan-2x & indica & 10 & Xichuan-4x & indica \\
\hline 11 & Dayebai-2x & indica & 11 & Dayebai-4x & indica \\
\hline
\end{tabular}

\section{Statistical analysis}

Agronomic traits data was analyzed using SPSS and the statistical significances were determined using Paired- $T$ test by SPSS version 17.0. Levels of heterosis were measured as heterobeltiosis, which is the superiority of a hybrid over the better parent, and competitive heterosis, which is calculated by comparing autotetraploid rice hybrids with their corresponding diploid hybrids. Correlation analysis between the genetic distance and heterobeltiosis was performed with SPSS version 17.0.

Number of effective alleles per locus $(A e)$, expected heterozygosity $(\mathrm{He})$ and Shannon's information index
(I) were calculated to measure the genetic variation in diploid and autotetraploid rice. Analyses of these computations were assessed using the program POP GENE version 1.32 (Yeh et al. 1997). Polymorphism information content (PIC) was calculated according to the formula: $\mathrm{PIC}_{i}=1-\sum P_{i j}^{2} \quad(j=1)$ (Anderson et al. 1993) and genetic distance was estimated according to the method of Nei (1978). Neighbor-joining (NJ) tree was constructed by Software NTSYS version 2.10e (Exeter Software, Setauket, NY USA) on the basis of similarity measures (Rohlf 2002), and MEGA V4.0 was used to observe the NJ tree (Tamura et al. 2007).

Table 3 Genetic variation in agronomic traits of diploid and autotetraploid rice

\begin{tabular}{|c|c|c|c|c|c|c|c|c|}
\hline \multirow[t]{2}{*}{ Traits } & \multicolumn{3}{|c|}{ Diploid } & \multicolumn{3}{|c|}{ Autotetraploid } & \multirow[t]{2}{*}{$t$} & \multirow[t]{2}{*}{$\mathbf{P}$} \\
\hline & Mean & Range & CV (\%) & Mean & Range & CV (\%) & & \\
\hline $\mathrm{PH}$ & 99.51 & $66.67-152.00$ & 20.60 & 90.63 & 70.83-137.67 & 15.61 & -2.168 & $0.036^{*}$ \\
\hline$P L$ & 22.22 & 14.59-35.87 & 17.89 & 25.12 & $18.58-31.34$ & 10.49 & 3.684 & $0.001^{* *}$ \\
\hline EPN & 7.10 & 4.33-11.00 & 23.35 & 5.09 & $2.33-8.33$ & 31.58 & -4.874 & $1.964 \mathrm{E}-5^{* *}$ \\
\hline TGP & 514.21 & 281.00-946.33 & 29.93 & 420.17 & 206.67-704.00 & 31.17 & -3.136 & $0.003^{* *}$ \\
\hline GPP & 128.07 & $82.67-229.00$ & 27.10 & 90.08 & $54.00-142.56$ & 28.84 & -5.279 & $1.340 E-6^{* *}$ \\
\hline FLL & 33.93 & $18.63-46.90$ & 20.00 & 37.06 & $26.33-48.23$ & 14.56 & 1.763 & 0.086 \\
\hline FLW & 1.68 & $1.17-2.23$ & 14.19 & 1.75 & $1.30-2.27$ & 14.52 & 1.221 & 0.230 \\
\hline GL & 7.88 & $6.15-11.97$ & 16.13 & 9.69 & $8.00-12.92$ & 11.79 & 5.677 & $1.580 \mathrm{E}-6^{* *}$ \\
\hline GW & 2.84 & $2.00-3.53$ & 16.40 & 3.17 & $2.20-4.10$ & 13.60 & 4.044 & $2.478 \mathrm{E}-4^{* *}$ \\
\hline L/W & 2.89 & $1.74-5.07$ & 28.98 & 3.13 & $2.14-4.83$ & 20.81 & 1.309 & 0.198 \\
\hline GD & 58.20 & $37.40-92.90$ & 24.70 & 35.80 & $24.4-53.80$ & 25.60 & -8.321 & 4.347E-10** \\
\hline GY & 2.98 & $0.63-5.74$ & 35.89 & 1.50 & $0.11-4.97$ & 72.21 & -6.357 & $1.843 E-7^{* *}$ \\
\hline GWT & 24.49 & 19.60-43.03 & 18.26 & 33.88 & $28.30-52.80$ & 14.72 & 9.041 & $5.209 \mathrm{E}-11^{* *}$ \\
\hline SS (\%) & 79.29 & $25.68-96.76$ & 19.36 & 33.05 & $2.54-67.57$ & 52.43 & -11.282 & $1.076 \mathrm{E}-13^{* *}$ \\
\hline
\end{tabular}

*** Significantly different from zero at $\mathrm{P}<0.05$ and $\mathrm{P}<0.01$, respectively. $\mathrm{CV}=$ coefficient of variation.

$P H=$ plant height, $P L=$ panicle length, $E P N=$ effective panicles number, $T G P=$ total number of grains per plant, $G P P=$ grains per panicle, $F L L=$ flag leave length, $F L W=$ flag leave width, $G L=$ grain length, $G W=$ grain width, $L W=$ grain length to width, $G D=$ grain density, $G Y=$ grain yield, $G W T=1000-$ grain weight and SS = seed set ratio. 


\section{Results}

Analysis of agronomic traits

The mean values regarding the agronomic traits of diploid and autotetraploid rice were summarized in Table 3. There were greater differences in the agronomic traits of the diploid and autotetraploid rice. In comparison with the diploid rice, seven traits including GWT, FLL, FLW, PL, GL, GW and L/W showed better performance in autotetraploid than diploid rice. For instance, the mean value of GWT was 24.49 and ranged from 19.60 to 43.03 in diploid rice, while the mean value of GWT was 33.88 in autotetraploid rice and ranged from 28.30 to 52.80 . However, EPN, PH, SS, TGP, GPP, GY and GD decreased in autotetraploid rice, such as EPN, the mean value was 7.10 and ranged from 4.33 to 11.00 in diploid rice, while in autotetraploid rice the mean value was 5.09 and ranged from 2.33 to 8.33 .

In addition, Paired $T$-test was used to evaluate the variation of agronomic traits in different ploidy level. Among all the agronomic traits, we found that PL, TGP, EPN, GWT, GL, GW, GY, SS, GPP and GD showed highly significant $(\mathrm{P}<0.01)$ variation, while $\mathrm{PH}$, showed significant $(\mathrm{P}<0.05)$ variation in ploidy level comparison (Table 3).

\section{Detection of genetic variation in rice}

To detect the genetic variation among the cultivars, 99 microsatellites or simple sequence repeats (SSRs) markers were selected from the rice genome and uniformly distributed on all chromosomes. The results showed a higher variation in autotetraploid rice compared with the diploid rice (Table 4).

A total of 285 alleles were detected in 40 diploid cultivars, the number of alleles per locus $(A e)$ ranged from 2 to 5 , with a mean of 2.899 . The expected heterozygosity $\mathrm{He}$ ) in the present study ranged from 0.049 to 0.788 , with an average of 0.487 and Shannon's information index $(I)$ ranged from 0.117 to 1.578 , with an average of 0.819 in diploid rice. Polymorphism information content (PIC) values were ranged from 0.048 to 0.753 , with an average of 0.421 .

In autotetraploid rice, 291 alleles were detected and the number of alleles per locus ranged from 2 to 5 , with a mean frequency of 2.949. The expected heterozygosity ranged from 0.049 to 0.792 , with an average of 0.493 and $I$ was ranged from 0.117 to 1.664 , with an average of 0.822 , and PIC were ranged from 0.043 to 0.787 , with an average of 0.432 . Autotetraploid lines showed a higher number of $A e, H e, I$ and PIC than diploid cultivars.

In addition, we found that 10 SSR markers showed more variation in the number of alleles among 99 SSR markers. In comparison with the diploid rice, seven markers RM443, RM22, RM559, PSM383, RM13, RM340 and PSM410 showed high number of alleles in
Table 4 Genetic diversity and genetic variation detected by SSR markers in diploid and autotetraploid rice

\begin{tabular}{|c|c|c|c|c|c|c|c|c|c|}
\hline \multirow{2}{*}{$\begin{array}{l}\text { SSR } \\
\text { Primers }\end{array}$} & \multirow[t]{2}{*}{$\mathrm{Chr}^{\mathrm{a}}$} & \multicolumn{4}{|c|}{ Diploid } & \multicolumn{4}{|c|}{ Autotetraploid } \\
\hline & & $A e^{\mathrm{b}}$ & $H e^{c}$ & $I^{d}$ & $\mathrm{PIC}^{\mathrm{e}}$ & $A e$ & $\mathrm{He}$ & $I$ & PIC \\
\hline PSM41 & 1 & 5 & 0.735 & 1.471 & 0.699 & 5 & 0.729 & 1.451 & 0.691 \\
\hline M23 & 1 & 3 & 0.599 & 0.978 & 0.513 & 3 & 0.647 & 1.067 & 0.571 \\
\hline V443 & 1 & 2 & 0.555 & 0.882 & 0.456 & 3 & 0.561 & 0.942 & 0.493 \\
\hline M104 & 1 & 2 & 0.469 & 0.662 & 0.349 & 2 & 0.375 & 0.562 & 0.305 \\
\hline M237 & 1 & 2 & 0.302 & 0.479 & 0.256 & 2 & 0.332 & 0.515 & 0.277 \\
\hline M262 & 2 & 4 & 0.705 & 1.303 & 0.656 & 4 & 0.669 & 1.215 & 0.613 \\
\hline M341 & 2 & 3 & 0.599 & 0.980 & 0.505 & 3 & 0.515 & 0.824 & 0.424 \\
\hline M109 & 2 & 3 & 0.477 & 0.831 & 0.428 & 3 & 0.453 & 0.801 & 0.409 \\
\hline SM122 & 2 & 3 & 0.619 & 1.018 & 0.539 & 3 & 0.611 & 1.011 & 0.536 \\
\hline M498 & 2 & 3 & 0.542 & 0.884 & 0.457 & 3 & 0.492 & 0.800 & 0.411 \\
\hline M29 & 2 & 2 & 0.499 & 0.693 & 0.375 & 2 & 0.485 & 0.678 & 0.368 \\
\hline M526 & 2 & 2 & 0.498 & 0.691 & 0.374 & 2 & 0.497 & 0.690 & 0.373 \\
\hline M211 & 2 & 2 & 0.485 & 0.678 & 0.368 & 2 & 0.455 & 0.647 & 0.352 \\
\hline M106 & 2 & 2 & 0.368 & 0.555 & 0.300 & 2 & 0.432 & 0.624 & 0.339 \\
\hline SM379 & 3 & 5 & 0.788 & 1.578 & 0.753 & 5 & 0.681 & 1.256 & 0.622 \\
\hline M168 & 3 & 4 & 0.572 & 1.062 & 0.525 & 4 & 0.469 & 0.887 & 0.431 \\
\hline רברי & 3 & 3 & 0.559 & 0.899 & 0.466 & 4 & 0.639 & 1.162 & 0.579 \\
\hline M232 & 3 & 3 & 0.401 & 0.679 & 0.345 & 3 & 0.384 & 0.703 & 0.351 \\
\hline RM156 & 3 & 3 & 0.444 & 0.780 & 0.398 & 3 & 0.494 & 0.849 & 0.438 \\
\hline PSM381 & 3 & 3 & 0.656 & 1.081 & 0.581 & 3 & 0.662 & 1.091 & 0.588 \\
\hline M565 & 3 & 3 & 0.226 & 0.461 & 0.214 & 3 & 0.536 & 0.916 & 0.478 \\
\hline 1282 & 3 & 3 & & 0.998 & 0.526 & 2 & 0.435 & 0.627 & 0.341 \\
\hline SM429 & 3 & 2 & 0.455 & 0.647 & 0.352 & 2 & 0.420 & 0.611 & 0.332 \\
\hline M175 & 3 & 2 & 0.049 & 0.117 & 0.048 & 2 & 0.051 & 0.122 & 0.050 \\
\hline RM468 & 3 & 2 & 0.245 & 0.410 & 0.215 & 2 & 0.307 & 0.485 & 0.260 \\
\hline M416 & 3 & 2 & 0.400 & 0.589 & 0.320 & 2 & 0.353 & 0.538 & 0.291 \\
\hline RM60 & 3 & 2 & 0.051 & 0.122 & 0.050 & 2 & 0.512 & 0.613 & 0.043 \\
\hline M307 & 4 & 5 & 0.668 & 1.268 & 0.608 & 5 & 0.498 & 0.845 & 0.436 \\
\hline MM241 & 4 & 4 & 0.479 & 0.879 & 0.427 & 4 & 0.704 & 1.477 & 0.647 \\
\hline RM559 & 4 & 2 & 0.129 & 0.624 & 0.422 & 3 & 0.451 & 0.722 & 0.514 \\
\hline PSM194 & 4 & 3 & 0.547 & 0.932 & 0.488 & 3 & 0.508 & 0.781 & 0.404 \\
\hline MM255 & 4 & 2 & 0.293 & 0.469 & 0.250 & 2 & 0.208 & 0.362 & 0.186 \\
\hline RM471 & 4 & 2 & 0.394 & 0.584 & 0.317 & 2 & 0.495 & 0.688 & 0.372 \\
\hline RM261 & 4 & 2 & 0.478 & 0.671 & 0.364 & 2 & 0.278 & 0.451 & 0.239 \\
\hline PSM196 & 4 & 2 & 0.368 & 0.555 & 0.300 & 2 & 0.496 & 0.690 & 0.373 \\
\hline PSM133 & 4 & 2 & 0.260 & 0.429 & 0.226 & 2 & 0.488 & 0.681 & 0.369 \\
\hline RM273 & 4 & 2 & 0.191 & 0.341 & 0.173 & 2 & 0.412 & 0.602 & 0.327 \\
\hline RM164 & 5 & 4 & 0.724 & 1.327 & 0.672 & 4 & 0.681 & 1.261 & 0.632 \\
\hline RM480 & 5 & 4 & 0.698 & 1.268 & 0.641 & 4 & 0.543 & 1.010 & 0.495 \\
\hline RM31 & 5 & 4 & 0.650 & 1.166 & 0.585 & 4 & 0.719 & 1.314 & 0.665 \\
\hline RM122 & 5 & 3 & 0.513 & 0.785 & 0.406 & 3 & 0.495 & 0.688 & 0.372 \\
\hline RM249 & 5 & 3 & 0.579 & 0.963 & 0.506 & 3 & 0.605 & 1.008 & 0.534 \\
\hline
\end{tabular}


Table 4 Genetic diversity and genetic variation detected by SSR markers in diploid and autotetraploid rice (Continued)

\begin{tabular}{|c|c|c|c|c|c|c|c|c|c|}
\hline PSM383 & 5 & 2 & 0.428 & 0.619 & 0.336 & 3 & 0.447 & 0.714 & 0.368 \\
\hline RM13 & 5 & 2 & 0.497 & 0.690 & 0.373 & 3 & 0.516 & 0.785 & 0.406 \\
\hline RM574 & 5 & 2 & 0.469 & 0.662 & 0.359 & 2 & 0.478 & 0.671 & 0.364 \\
\hline RM527 & 6 & 5 & 0.704 & 1.346 & 0.654 & 5 & 0.792 & 1.664 & 0.787 \\
\hline RM276 & 6 & 5 & 0.747 & 1.461 & 0.704 & 5 & 0.726 & 1.433 & 0.684 \\
\hline RM528 & 6 & 3 & 0.604 & 1.010 & 0.536 & 3 & 0.639 & 1.055 & 0.563 \\
\hline PSM138 & 6 & 3 & 0.566 & 0.919 & 0.477 & 3 & 0.573 & 0.922 & 0.479 \\
\hline RM510 & 6 & 3 & 0.529 & 0.808 & 0.418 & 3 & 0.570 & 0.947 & 0.496 \\
\hline RM340 & 6 & 3 & 0.474 & 0.807 & 0.414 & 4 & 0.575 & 1.063 & 0.526 \\
\hline RM275 & 6 & 2 & 0.149 & 0.281 & 0.138 & 2 & 0.284 & 0.458 & 0.244 \\
\hline RM103 & 6 & 2 & 0.334 & 0.517 & 0.278 & 2 & 0.368 & 0.555 & 0.300 \\
\hline PSM142 & 7 & 4 & 0.725 & 1.335 & 0.675 & 4 & 0.726 & 1.339 & 0.676 \\
\hline RM248 & 7 & 4 & 0.688 & 1.219 & 0.624 & 4 & 0.645 & 1.158 & 0.577 \\
\hline PSM147 & 7 & 3 & 0.528 & 0.805 & 0.416 & 3 & 0.355 & 0.540 & 0.244 \\
\hline RM234 & 7 & 2 & 0.467 & 0.660 & 0.358 & 2 & 0.415 & 0.606 & 0.329 \\
\hline RM560 & 7 & 2 & 0.157 & 0.293 & 0.144 & 2 & 0.165 & 0.305 & 0.496 \\
\hline RM455 & 7 & 2 & 0.450 & 0.642 & 0.349 & 2 & 0.478 & 0.671 & 0.526 \\
\hline RM44 & 8 & 4 & 0.397 & 0.761 & 0.363 & 4 & 0.260 & 0.429 & 0.226 \\
\hline RM210 & 8 & 3 & 0.526 & 0.836 & 0.431 & 3 & 0.542 & 0.884 & 0.684 \\
\hline RM152 & 8 & 3 & 0.539 & 0.851 & 0.439 & 3 & 0.571 & 0.918 & 0.676 \\
\hline RM458 & 8 & 2 & 0.255 & 0.423 & 0.223 & 2 & 0.420 & 0.611 & 0.300 \\
\hline RM408 & 8 & 2 & 0.432 & 0.624 & 0.339 & 2 & 0.367 & 0.554 & 0.329 \\
\hline PSM151 & 8 & 2 & 0.452 & 0.644 & 0.350 & 2 & 0.426 & 0.617 & 0.577 \\
\hline RM126 & 8 & 2 & 0.480 & 0.673 & 0.365 & 2 & 0.301 & 0.478 & 0.255 \\
\hline RM256 & 8 & 2 & 0.049 & 0.117 & 0.048 & 2 & 0.049 & 0.117 & 0.048 \\
\hline RM242 & 9 & 4 & 0.637 & 1.153 & 0.573 & 4 & 0.477 & 0.825 & 0.407 \\
\hline RM257 & 9 & 4 & 0.547 & 0.997 & 0.490 & 3 & 0.528 & 0.868 & 0.449 \\
\hline PSM399 & 9 & 3 & 0.535 & 0.878 & 0.454 & 3 & 0.374 & 0.688 & 0.343 \\
\hline PSM340 & 9 & 3 & 0.595 & 0.995 & 0.526 & 3 & 0.562 & 0.917 & 0.476 \\
\hline RM553 & 9 & 3 & 0.611 & 1.011 & 0.536 & 3 & 0.447 & 0.714 & 0.368 \\
\hline RM434 & 9 & 3 & 0.418 & 0.719 & 0.365 & 3 & 0.500 & 0.693 & 0.375 \\
\hline PSM160 & 9 & 2 & 0.486 & 0.679 & 0.368 & 2 & 0.482 & 0.675 & 0.366 \\
\hline RM591 & 10 & 5 & 0.785 & 1.572 & 0.751 & 5 & 0.744 & 1.472 & 0.704 \\
\hline PSM166 & 10 & 3 & 0.607 & 0.996 & 0.525 & 3 & 0.586 & 0.958 & 0.501 \\
\hline RM258 & 10 & 3 & 0.516 & 0.860 & 0.444 & 2 & 0.272 & 0.443 & 0.235 \\
\hline PSM163 & 10 & 2 & 0.266 & 0.436 & 0.231 & 2 & 0.420 & 0.611 & 0.332 \\
\hline PSM169 & 10 & 2 & 0.500 & 0.693 & 0.375 & 2 & 0.334 & 0.517 & 0.278 \\
\hline RM484 & 10 & 2 & 0.180 & 0.325 & 0.164 & 2 & 0.139 & 0.266 & 0.129 \\
\hline RM202 & 11 & 5 & 0.764 & 1.518 & 0.725 & 5 & 0.683 & 1.370 & 0.647 \\
\hline PSM365 & 11 & 5 & 0.749 & 1.477 & 0.708 & 5 & 0.727 & 1.405 & 0.682 \\
\hline $\mathrm{RM} 224$ & 11 & 5 & 0.740 & 1.467 & 0.700 & 5 & 0.718 & 1.362 & 0.666 \\
\hline PSM410 & 11 & 4 & 0.529 & 0.948 & 0.465 & 5 & 0.704 & 1.342 & 0.651 \\
\hline RM229 & 11 & 4 & 0.685 & 1.228 & 0.624 & 4 & 0.671 & 1.273 & 0.604 \\
\hline
\end{tabular}

Table 4 Genetic diversity and genetic variation detected by SSR markers in diploid and autotetraploid rice (Continued)

\begin{tabular}{|c|c|c|c|c|c|c|c|c|c|}
\hline PSM173 & 11 & 3 & 0.517 & 0.788 & 0.408 & 3 & 0.532 & 0.847 & 0.437 \\
\hline RM167 & 11 & 3 & 0.528 & 0.805 & 0.416 & 3 & 0.610 & 1.018 & 0.541 \\
\hline RM254 & 11 & 3 & 0.538 & 0.919 & 0.480 & 3 & 0.595 & 0.995 & 0.526 \\
\hline PSM411 & 11 & 3 & 0.580 & 0.943 & 0.491 & 3 & 0.637 & 1.057 & 0.565 \\
\hline PSM416 & 11 & 2 & 0.498 & 0.691 & 0.374 & 2 & 0.500 & 0.693 & 0.375 \\
\hline PSM188 & 12 & 3 & 0.586 & 0.984 & 0.520 & 3 & 0.635 & 1.046 & 0.557 \\
\hline RM19 & 12 & 3 & 0.541 & 0.856 & 0.432 & 3 & 0.553 & 0.896 & 0.464 \\
\hline RM101 & 12 & 3 & 0.610 & 1.001 & 0.528 & 3 & 0.614 & 1.013 & 0.536 \\
\hline PSM419 & 12 & 3 & 0.618 & 1.030 & 0.549 & 3 & 0.514 & 0.826 & 0.425 \\
\hline PSM420 & 12 & 3 & 0.141 & 0.314 & 0.133 & 3 & 0.441 & 0.706 & 0.364 \\
\hline PSM187 & 12 & 2 & 0.349 & 0.533 & 0.288 & 2 & 0.289 & 0.464 & 0.247 \\
\hline RM463 & 12 & 2 & 0.293 & 0.469 & 0.250 & 2 & 0.307 & 0.485 & 0.260 \\
\hline PSM191 & 12 & 2 & 0.202 & 0.355 & 0.182 & 3 & 0.245 & 0.472 & 0.226 \\
\hline PSM190 & 12 & 2 & 0.497 & 0.690 & 0.374 & 2 & 0.498 & 0.691 & 0.374 \\
\hline Mean & & 2.899 & 0.487 & 0.819 & 0.421 & 2.949 & 0.493 & 0.822 & 0.432 \\
\hline St. Dev & & 0.953 & 0.175 & 0.335 & 0.162 & 0.962 & 0.155 & 0.319 & 0.158 \\
\hline
\end{tabular}

autotetraploid rice, while RM282, RM257, RM258 showed more alleles in diploid rice. These results showed that there might be a genetic variation at DNA level, which leads to differentiation in the diploid and autotetraploid rice.

Phylogenetic analysis of diploid and autotetraploid rice We constructed a phylogenetic tree based on the SSR markers to evaluate the genetic variation between diploid and autotetraploid rice because SSR markers have a higher resolution in separating the different rice cultivars. Thirteen pairs of diploid and autotetraploid rice showed high similarity and grouped into the same clade, while other 27 pairs of autotetraploid and corresponding diploid rice cultivars were phylogenetically distinct from other cultivars and clustered together on a distinct branch of phylogenetic tree (Figure 1).

All autotetraploid and diploid rice cultivars were distinguished very well and clustered into two main groups, which were subdivided into smaller groups. Group I consisted of 34 autotetraploid and diploid rice cultivars, mainly belong to japonica subspecies. We can clearly distinguished two subgroups in Group I: Subgroup I-A mainly included 32 autotetraploid and corresponding diploid rice cultivars. Taichung 65-2x/Taichung 65-4x, E2-2×/E2-4x, E4-2×/E4-4x, E45-2×/E45-4×, E245-2× /E245-4×, Shennong 265-2×/Shennong 265-4×, L-202- 


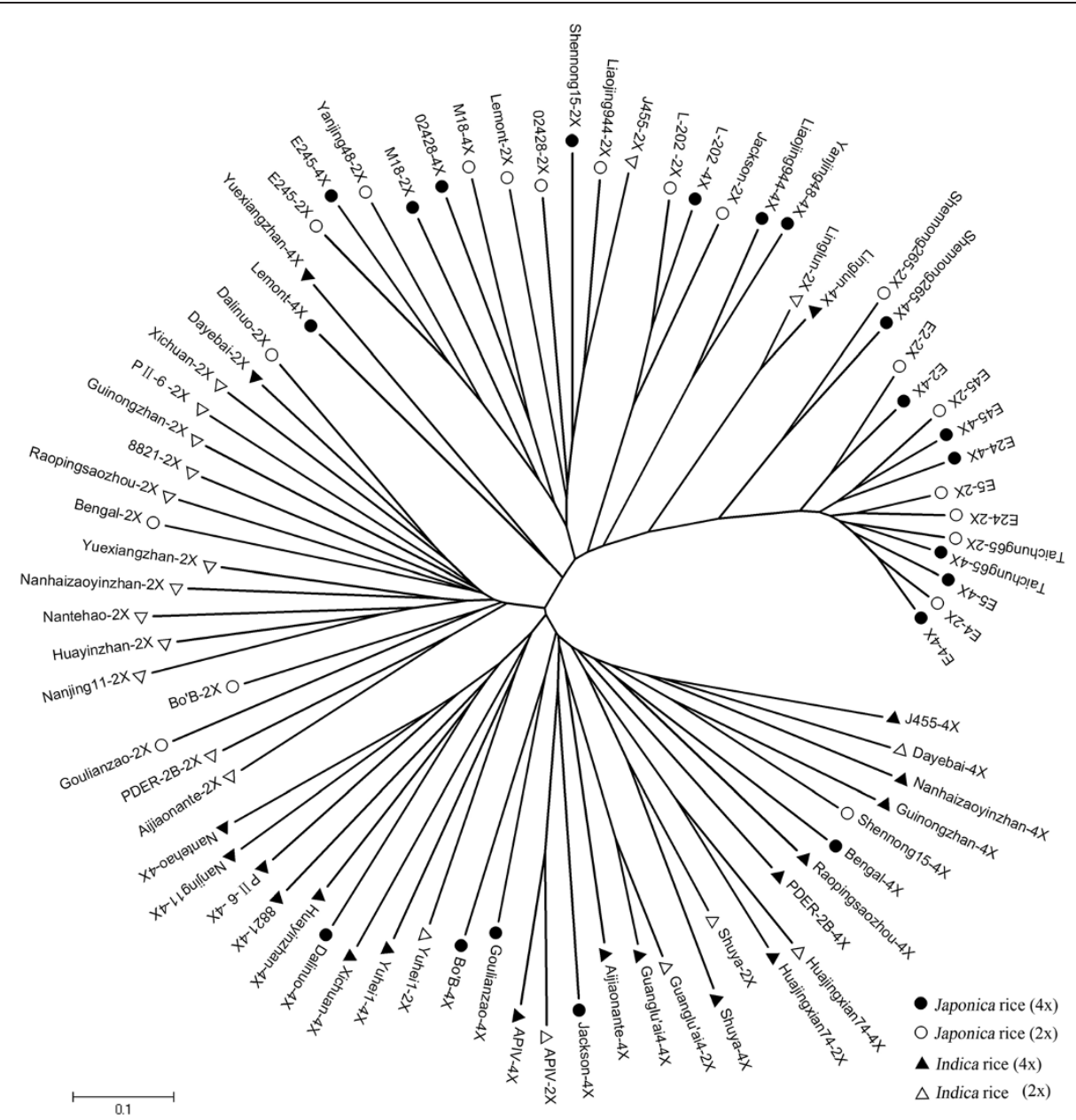

Figure 1 Unrooted neighbor-joining tree based on SSR markers showing relationships among 80 autotetraploid and diploid rice cultivars.

$2 \times /$ L-202-4 $\times$ and Linglun- $2 \times /$ Linglun $-4 \times$ showed closest relationship between diploid and autotetraploid rice, while E5-2x/E5-4x, E24-2×/E24-4×, Liaojing 944-2×

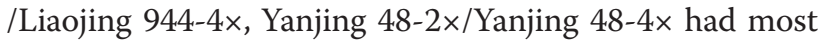
distant relationship and showed more variation in autotetraploid and diploid rice cultivars. Subgroup I-B only had 2 autotetraploid rice lines, which were Yuexiangzhan- $4 \times$ and Lemont- $4 \times$, both of them had a distant relationship from their original diploid rice.

Group II consisted of 46 cultivars of diploid and autotetraploid rice and most of them belong to indica subspecies. This group could be further subdivided into three subgroups: Subgroup II-A consisted of 20 cultivars, Subgroup II-B consisted of 9 cultivars and Subgroup II-C consisted of 17 cultivars. In the group II, only 5 pairs of corresponding diploid and autotetraploid rice such as Huajingxian 74-2 $\times$ /Huajingxian 74-4x, Shuya- $2 \times /$ Shuya $-4 \times$, Guanglu'ai $4-2 \times /$ Guanglu'ai $4-4 \times$, APIV-2 $\times /$ APIV $-4 \times$ and Yuhei $1-2 \times /$ Yuhei $1-4 \times$ showed the closest relationship with each other and other rice cultivars showed high variation and distant relationship between autotetraploid and their diploid counterparts.

\section{Heterosis analysis of diploid and autotetraploid rice}

To evaluate the heterosis level of inter-subspecific autotetraploid hybrids, eleven parents were selected based on the genetic distance of indica and japonica autotetraploid rice. A total of fifty four indica-japonica hybrids were developed by crossing four typical japonica rice cultivars with seven indica rice cultivars, and their corresponding diploid parents were used as control (Table 2).

Positive heterobeltiosis analysis revealed that most autotetraploid hybrids showed superior results than corresponding better parents for most of the agronomic traits and grain yield (Table 5 ). Twenty-five $F_{1}$ combinations showed significant and positive heterosis over the better parents in autotetraploid rice, and Shennong $15 \times$ Xichuan was identified as the best specific combination with the highest level of heterobeltiosis in autotetraploid hybrids (Figure 2). GY showed the highest heterosis 
Table 5 Analysis of heterobeltiosis and competitive heterosis for important agronomic traits in autotetraploid and diploid rice

\begin{tabular}{|c|c|c|c|c|c|c|c|c|c|c|c|c|}
\hline \multirow[t]{3}{*}{ Traits } & \multicolumn{8}{|c|}{ Heterobeltiosis (compared with better parent) } & \multirow{2}{*}{\multicolumn{4}{|c|}{$\begin{array}{c}\text { Competitive heterosis } \\
\text { (compared with corresponding diploid hybrids) }\end{array}$}} \\
\hline & \multicolumn{4}{|c|}{ Diploid } & \multicolumn{4}{|c|}{ Autotetraploid } & & & & \\
\hline & Minimum & Maximum & Mean & $+(-)^{\mathrm{a}}$ & Minimum & Maximum & Mean & $+(-)$ & Minimum & Maximum & Mean & $+(-)$ \\
\hline & \multicolumn{4}{|c|}{ 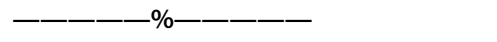 } & \multicolumn{4}{|c|}{-————-—-ー } & \multicolumn{4}{|c|}{ 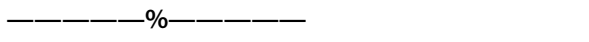 } \\
\hline$\overline{\mathrm{PH}}$ & -13.56 & 25.74 & 3.52 & $18(9)$ & -17.94 & 60.36 & 15.26 & $23(4)$ & -20.77 & 27.43 & -0.38 & $14(13)$ \\
\hline EPN & -42.00 & 147.83 & 13.83 & $14(13)$ & -82.84 & 11.76 & 10.17 & $11(16)$ & -79.45 & 11.22 & -35.78 & $1(26)$ \\
\hline$P L$ & -21.65 & 20.07 & -0.96 & $12(15)$ & -13.06 & 40.17 & 13.01 & $24(3)$ & 3.24 & 38.99 & 17.60 & $27(0)$ \\
\hline GPP & -22.36 & 142.45 & 34.03 & $20(7)$ & -63.39 & 50.29 & 17.91 & 18(9) & -80.73 & -5.57 & -46.30 & $0(27)$ \\
\hline GD & -41.46 & 30.01 & 0.22 & $11(16)$ & -49.44 & 13.74 & -26.31 & $1(26)$ & -62.92 & -13.88 & -40.83 & $0(27)$ \\
\hline GL & -25.92 & 3.39 & -5.08 & $3(24)$ & -16.96 & 7.10 & 2.77 & $9(18)$ & 10.64 & 57.23 & 24.43 & $27(0)$ \\
\hline GW & -26.90 & 4.44 & -3.86 & 8 (19) & -10.63 & 9.89 & 0.64 & $14(13)$ & -0.91 & 40.67 & 13.88 & $26(1)$ \\
\hline L/W & -42.41 & -2.51 & -14.98 & $0(27)$ & -33.63 & -3.46 & -18.42 & $0(27)$ & -3.55 & 39.73 & 10.51 & $25(2)$ \\
\hline GWT & -4.98 & 33.32 & 10.96 & $16(11)$ & -25.28 & 34.53 & 11.22 & $22(5)$ & -10.52 & 55.32 & 30.80 & $27(0)$ \\
\hline GY & -663.68 & 71.90 & -28.95 & $18(9)$ & -76.82 & 158.78 & 71.16 & $25(2)$ & -27.45 & 89.85 & 21.14 & $26(1)$ \\
\hline SS & -676.40 & -19.31 & -160.43 & $0(27)$ & -332.66 & 36.14 & -22.33 & $17(10)$ & -289.71 & 78.64 & 2.01 & 19(8) \\
\hline
\end{tabular}

${ }^{a}$ indicates increased (+) or decreased (-) effects in 27 hybrids.

$P H=$ plant height, $P L=$ panicle length, $E P N=$ effective panicles number, $G L=$ grain length, $G W=$ grain width, $L / W=$ grain length to width ratio, $G D=$ grain density, $G P P=$ grains per panicle, $G W T=1000$-grain weight, $G Y=$ grain yield and $S S=$ seed set ratio.

among all the traits, followed by GPP, PH, PL, SS, GWT, $\mathrm{GD}, \mathrm{EPN}, \mathrm{GW}, \mathrm{GL}$ and $\mathrm{L} / \mathrm{W}$ in autotetraploid rice. However the heterobeltiosis levels varied considerably in diploid rice, Liaojing $944 \times$ Xichuan exhibited the highest heterobeltiosis among diploid rice curtivars. EPN produced the highest heterosis among the all traits observed, followed by GPP, GY, GWT, GD, PH, PL, GW, $\mathrm{GL}, \mathrm{L} / \mathrm{W}$ and SS in diploid rice.

Competitive heterosis was used to further study the heterosis of autotetraploid and corresponding diploid rice hybrids (Table 5). For the competitive heterosis, most of agronomic traits such as PL (ranged from 3.24 to 38.99 with a mean of $17.60 \%$ ), GL (ranged from 10.64 to 57.23 and $24.43 \%$ ), GW (ranged from -0.91 to 40.67 with a mean of 13.88\%), L/W (ranged from -3.55 to 39.73 with a mean of $10.51 \%$ ), SS (ranged from -289.71 to 78.64 with a mean of $2.01 \%$ ) and GWT (ranged from -10.52 to 55.32 with a mean of $30.8 \%$ ) showed positive competitive heterosis or increased effects in autotetraploid rice hybrids among the agronomic traits. Yield also exhibited positive competitive heterosis and ranged from -27.45 to 89.85 , with an average of $21.14 \%$. However, $\mathrm{PH}$ (ranged from -20.77 to 27.43 with a mean of $-0.38 \%$ ), EPN (ranged from -79.45 to 11.22 with a mean of $-35.78 \%$ ), GPP (ranged from -80.73 to $-5.57 \%$ with a mean of $-46.30 \%$ ) and GD (ranged from -62.92 to -13.88 with a mean of $-40.83 \%$ ) showed reduction in competitive heterosis in autotetraploid rice hybrids. Twenty two hybrids showed significant and positive heterosis over the diploid hybrids, whereas only five autotetraploid hybrids depicted reduction in competitive heterosis.

\section{Correlation analysis of yield and genetic diversity with} agronomic traits

Grain yield and genetic distances based on SSR markers were used for correlation with heterosis in diploid and autotetraploid rice (Table 6). The correlation between SSR marker distance and heterobeltiosis for all the agronomic traits was non-significant in diploid rice, indicating that prediction of hybrid performance using SSR markers in diploid rice is low. The relationship between genetic distance and heterobeltiosis for most of agronomic traits was also non-significant in autotetraploid rice. However, it was significantly and positively correlated for grain length $(\mathrm{P}<0.01,0.514)$ and grain length to width ratio $(\mathrm{P}<0.05,0.412)$ in autotetraploid hybrids. The linear regression analysis between genetic distance and yield heterobeltiosis was positive and non-significant with $R^{2}$ value of 0.1036 in diploid rice, while significant and positive relationship was found in autotetraploid rice (Figure 3, Table 6). The correlations of grain yield heterobeltiosis with agronomic traits markedly differed in diploid and autotetraploid rice. For yield, autotetraploid rice showed significant correlations with EPN, GW and GWT, while yield showed significant correlations with $\mathrm{GD}$ and $\mathrm{L} / \mathrm{W}$ in diploid rice.

\section{Discussion}

Genetic variation in diploid and autotetraploid rice

The analysis of genetic variation among different genotypes provides basic information about the germplasm enhancement for breeding. Autotetraploid rice with doubling of chromosomes showed a higher variation in 


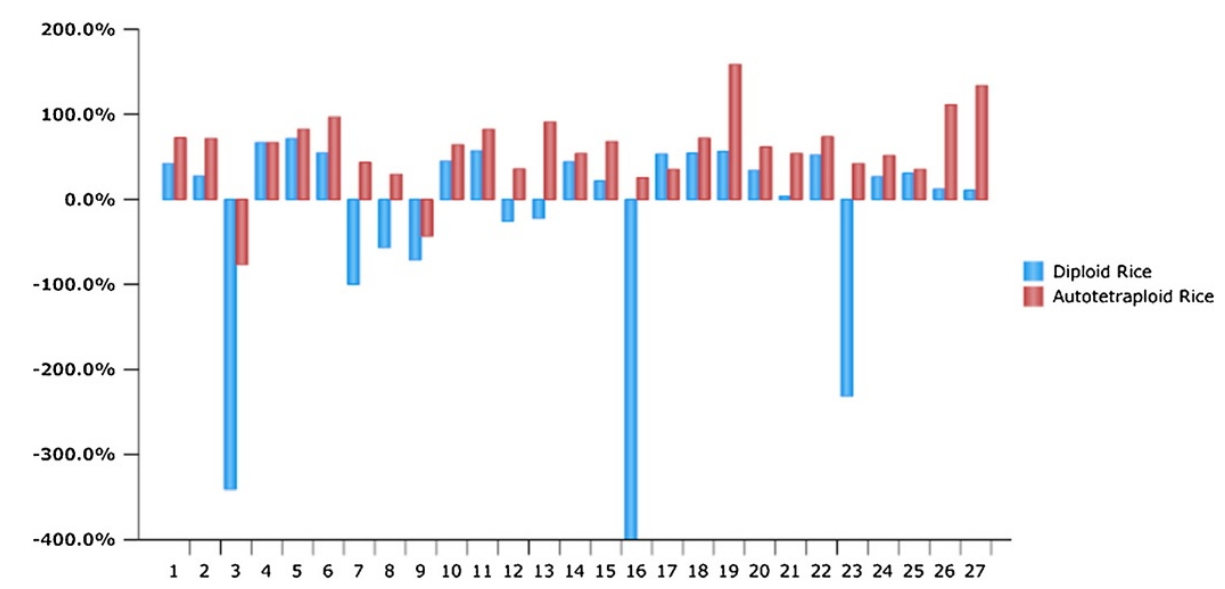

Figure 2 Graphical representation of heterobeltiosis for grain yield in $F_{1}$ hybrids of autotetraploid and diploid rice. Columns 1-27 indicate inter-subspecific hybrids of autotetraploid and their counterpart diploid genotypes: Liaojing $944 \times$ Aijiaonante, Liaojing $944 \times$ Guanglu'ai 4, Liaojing $944 \times$ PDER-2B, Liaojing $944 \times$ Raopingsaozhou, Liaojing $944 \times$ Xichuan, Liaojing $944 \times$ Dayebai, Yanjing $48 \times$ Aijiaonante, Yanjing $48 \times$ Guanglu'ai 4, Yanjing $48 \times$ PDER-2B, Yanjing $48 \times$ Raopingsaozhou, Yanjing $48 \times$ Nanhaizaoyinzhan, Yanjing $48 \times$ Xichuan, Yanjing $48 \times$ Dayebai, Shennong $15 \times$ Aijiaonante, Shennong $15 \times$ Guanglu'ai 4, Shennong $15 \times$ PDER-2B, Shennong $15 \times$ Raopingsaozhou, Shennong $15 \times$ Nanhaiza oyinzhan, Shennong $15 \times$ Xichuan, Shennong $15 \times$ Dayebai, Taichung $65 \times$ Aijiaonante, Taichung $65 \times$ Guanglu'ai 4, Taichung $65 \times$ PDER-2B, Taichung $65 \times$ Raopingsaozhou, Taichung $65 \times$ Nanhaizaoyinzhan, Taichung $65 \times$ Xichuan and Taichung $65 \times$ Dayebai.

agronomic traits, cellular level, quality and molecular level (Song and Zhang 1992; Luan et al. 2008). In the present study, autotetraploid rice had higher 1000-grain weight, grain length and grain width, but lower effective spikelet number, number of total panicles per plant and seed set ratio. In comparison with the diploid rice, production-related agronomic traits mainly occurred in autotetraploid rice. Therefore, 14 production-related agronomic traits were used to evaluate the phenotypic variation, and the results showed that there was a significant difference in diploid and autotetraploid rice for all agronomic traits under study. These results are in agreement with other studies, that autotetraploid showed significant variation in agronomic traits than their diploid counter parts (Tu et al. 2007; Shahid et al. 2011).
SSR markers showed a high polymorphism in the rice genome, which can offer unique opportunity for studying rice genotypes, genetic variation and genetic relationship (McCouch et al. 2002; Shah et al. 2013). Therefore, we used the SSR markers to evaluate the genetic variation of diploid and autotetraploid rice. The SSR results indicated that alleles per locus, expected heterozygosity, Shannon's information index and polymorphism information contents were higher in autotetraploid than diploid rice. Moreover, phylogenetic tree was constructed based on SSR markers and it revealed that most of autotetraploid rice genotypes are genetically isolated from corresponding diploid cultivars, and only thirteen pairs of corresponding diploid and autotetraploid rice showed a high similarity phylogenetic

Table 6 Correlation coefficients of grain yield and genetic distance with important agronomic traits on the basis of heterobeltiosis in diploid and autotetraploid rice

\begin{tabular}{lllll}
\hline Traits & \multicolumn{2}{c}{ Grain Yield } & \multicolumn{2}{c}{ Genetic distance } \\
\cline { 2 - 5 } & Diploid & Autotetraploid & Diploid & 0.246 \\
\hline PH & 0.040 & -0.051 & -0.014 & -0.072 \\
EPN & -0.151 & $0.541^{* *}$ & -0.253 & 0.221 \\
PL & 0.005 & 0.114 & -0.180 & 0.102 \\
TGP & 0.178 & 0.152 & -0.256 & -0.191 \\
GD & $0.586^{* *}$ & 0.186 & 0.292 & $0.514^{* *}$ \\
GL & -0.097 & -0.057 & 0.064 & -0.181 \\
GW & -0.198 & $0.367^{*}$ & -0.112 & $0.412^{*}$ \\
L/W & $-0.389^{*}$ & -0.263 & -0.009 & 0.076 \\
GWT & 0.349 & $0.528^{* *}$ & 0.088 & \\
\hline
\end{tabular}

*** Significantly different from zero at $\mathrm{P}<0.05$ and $\mathrm{P}<0.01$, respectively. See Table 5 for traits abbreviations. 


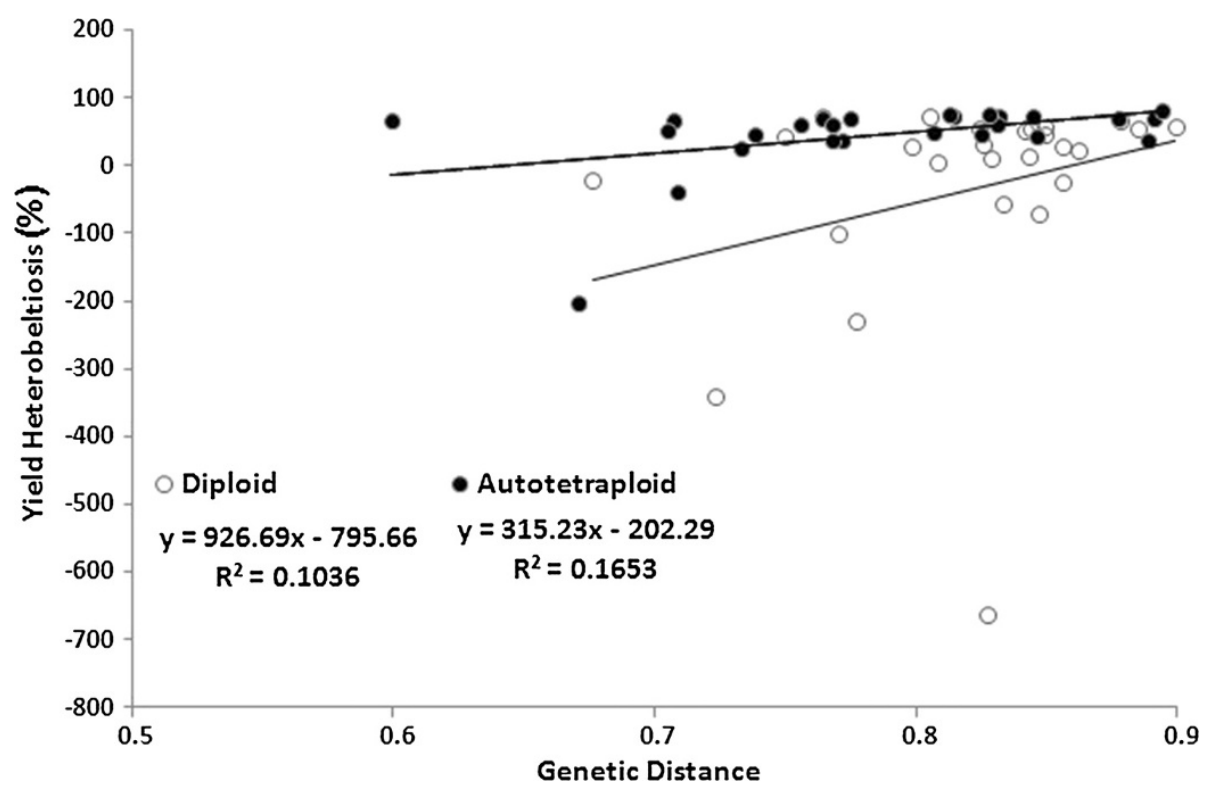

Figure 3 A regression correlation analysis between genetic distance and yield heterobeltiosis in inter-subspecific hybrids of diploid and autotetraploid rice.

relationship and grouped into the same clade. This finding is consistent with previous study that autotetraploid rice showed more genetic variation than diploid rice (Luan et al. 2008). Interestingly, both phenotypic and genotypic data showed a greater genetic variation in autotetraploid rice than diploid counterpart. These results suggested that there might be chromosome alteration or DNA sequence changes in autotetraploid rice that need further study, using functional molecular markers and SNP markers to analyze specific traits of autotetraploid rice.

Heterosis and genetic relationship in autotetraploid rice Hybrid breeding is one of the best techniques to increase the crop yield and it is successfully being used for many crops in China. Asian cultivated rice, indica and japonica, showed high hybrid vigor and numerous studies have been done to utilize the heterosis of these subspecies in diploid rice. However, little is known about autotetraploid rice and one of the major aim is the development of $F_{1}$ hybrids to utilize the advantage of polyploidy and indica-japonica heterosis. Inter-subspecific autotetraploid rice hybrids had shown stronger yield potential and greater adaptability compared with diploid rice (Shahid et al. 2011). Previous studies demonstrated high heterosis for panicles, 1000-grain weight, grain length and grain width in autotetraploid rice (Shahid et al. 2011, 2012) and three-line hybrid system had been already established in autotetraploid rice ( $\mathrm{Tu}$ et al. 2007). Therefore, we selected several typical indica and japonica autotetraploid and diploid rice cultivars based on genetic distance of indica and japonica rice varieties to study the heterosis in autotetraploid rice. Higher competitive heterosis and heterobeltiosis was found in autotetraploid than diploid rice. Heterobeltiosis for most of the agronomic traits, including PH, PL, GL, SS, GW, GY and GWT, was positive and showed a higher proportion in autotetraploid hybrids than diploid hybrids. In general, the results of the present study were in agreement with earlier investigations for autotetraploid rice hybrids (Tu et al. 2007; Shahid et al. 2011). In addition, autotetraploid rice hybrids also showed positive competitive heterosis or increased effects among the agronomic traits than diploid rice hybrids. For example, all autotetraploid hybrids (except one) showed significant and positive heterosis over the corresponding diploid hybrids for grain yield. From these results, we speculated that higher genetic variation in autotetraploid rice might be the result of changes in DNA structure of autotetraploid rice.

To increase the hybrid breeding efficiency, DNA markers have been used to investigate the parental genetic distance and its relationship with heterosis (Caruso et al. 2010). Previous studies showed that heterosis mainly depends on the genetic variation and traits of the parent's interaction, the greater the genetic variation and genetic distance, the more obvious hybrid vigour (Zhang et al. 1994). Numerous studies are available for evaluating usefulness of DNA markers for predicting heterosis and hybrid performance in diploid rice and other crops. There are two contradicting theories about heterosis prediction, some scientists suggested that molecular markers could be used for predicting heterosis (Smith et al. 1990; Zhang et al. 1994; Zha et al. 2008; Jaikishan et al. 2010), while other suggested that 
heterosis could not be predicted through molecular markers (Joshi et al. 2001). In the present study, SSR markers were employed to predict the heterosis in autotetraploid and diploid rice. The results from this study demonstrated non-significant correlation between genetic distance and heterosis for all agronomic traits and yield in diploid rice. This finding is consistent with other conclusions on the relationship between genetic distance and heterosis; especially in inter-subspecific hybrids of rice (Xiao et al. 1996; Zhang et al. 2007; Xangsayasane et al. 2010). SSR markers-based genetic distance might not be a reliable tool in hybrid breeding. Non-significant relationship between SSR markers diversity and heterosis could be because SSR diversity represented a genomewide diversity, whereas heterozygous loci for each trait could be localized to a specific region (Jaikishan et al. 2010). In this study, correlation between molecular marker distance and yield heterobeltiosis was significant in autotetraploid rice. Grain length and grain length to width ratio also depicted significant relationship with genetic distance, while all other traits showed nonsignificant relationships. These results are in agreement with previous reports on some other polyploid crops such as wheat, cotton, sugarcane and Indian mustard, who also found significant correlation between markers diversity and some traits understudy (Martin et al. 1995; Zhang et al. 2007). The maximum heterobeltiosis was recorded from genetically far distant autotetraploid and diploid parents. There had been no investigations to assess the relationship between genetic distance and hybrid performance in autotetraploid rice. In the present study, molecular markers were not suitable for prediction of hybrid performance for most of the traits, however, marker-based genetic distance showed a significant relation with yield heterosis, grain length and grain length to width ratio in autotetraploid parents. The information generated from this study will be useful for future autotetraploid rice breeding plans.

In summary, SSR markers are very useful to find genetic variation and phylogenetic analysis in different ploidy level, but they are not a reliable tool to predict heterosis for yield and other complex traits in diploid rice. Autotetraploid lines showed greater genetic differentiations which we can't find in diploid rice and both have a marked difference in their gene pool. Therefore, these results suggest that autotetraploid rice is an important germplasm for breeding and molecular studies. We could improve the rice cultivars through autotetraploid rice breeding for various important traits because autotetraploid rice had great stability across varying environments, resistant to lodging, greater grain length and width and resistant to insect pest and diseases. This may be an advantage to breed higher yield and better quality rice through autotetraploid rice breeding.

\section{Abbreviations}

Ae: Number of effective alleles per locus; EPN: Effective panicles number; FLL: Flag leave length; FLW: Flag leave width; GD: Grain density; GL: Grain length; GPP: Grains per panicle; GW: Grain width; GWT: 1000-grain weight; GY: Grain yield; He: Expected heterozygosity; L/W: Grain length to width ratio; PH: Plant height; PL: Panicle length; PIC: Polymorphism information content; TGP: Total number of grains per plant; I: Shannon's information index; SS: Seed set ratio.

\section{Competing interests}

The authors declare that they have no competing interests.

\section{Authors' contributions}

JWW, CYH, MQS, HBG, YXZ, XDL, YGL designed and carry out the experiments; JWW, MQS, XDL, YGL conducted the analysis of data and drafted the manuscript; also revised the manuscript. All authors read and approved the final manuscript.

\section{Acknowledgments}

The authors appreciated the supports from Prof. ZHANG Guiquan, DING Xiaohua and HAN Longzhi (China National Micro-core Rice Collection) for donating the near isogenic lines and some rice lines. We also thank Dr. CHEN Zhixiong, Dr. WANG Lan, Dr. FU Xuelin, Ms. ZHAO Xingjuan and YU Shuhong for technical assistance. This work was supported by the NSFC (30971756), the Doctoral Scientific Fund Project of the Ministry of Education of China and the Guangdong Provincial Key Science Foundation.

Received: 14 May 2013 Accepted: 2 September 2013

Published: 5 September 2013

\section{References}

Anand D, Prabhu KV, Singh AK (2012) Analysis of molecular diversity and fingerprinting of commercially grown Indian rice hybrids. J Plant Biochem Biotechnol 21:173-179

Anderson JA, Churchill GA, Autrique JE, Tanksley SD, Sorrells ME (1993) Optimizing parental selection for genetic linkage maps. Genome 36:181-186 Betrán FJ, Ribaut JM, Beck D, Gonzalez de León D (2003) Genetic diversity, specific combining ability, and heterosis in tropical maize under stress and nonstress environments. Crop Sci 43:797-806

Bingham ET, Groose RW, Woodfield DR, Kidwell KK (1994) Complementary gene interactions in alfalfa are greater in autotetraploids than diploids. Crop Sci 34:823-829

Caruso M, Curro S, Las Casas G, La Malfa S, Gentile A (2010) Microsatellite markers help to assess genetic diversity among Opuntia ficus indica cultivated genotypes and their relation with related species. Plant Syst Evol 290:85-97

Chen X, Temnykh S, Xu Y, Cho YG, McCouch SR (1997) Development of a microsatellite framework map providing genome-wide coverage in rice (Oryza sativa L.). Theor Appl Genet 9:553-567

Cheng SH, Cao LY, Zhuang JY, Chen SG, Zhan XD, Fan YY, Zhu DF, Min SK (2007) Super hybrid rice breeding in China: achievements and prospects. J Integr Plant Biol 49:805-810

Doyle JJ, Flagel LE, Paterson AH, Rapp RA, Soltis DE, Soltis PS, Wendel JF (2008) Evolutionary genetics of genome merger and doubling in plants. Genetics 42:443-461

Han LZ, Wei XH (2006) Descriptors and data standard for rice (Oryza sativa L.). China Agricultural Press, Beijing

Hu CY, Zeng YX, Lu YG, Li JQ, Liu XD (2009) High embryo sac fertility and diversity of abnormal embryo sacs detected in autotetraploid indica/japonica hybrids in rice by whole-mount eosin B-staining confocal laser scanning microscopy. Plant Breed 128:187-192

Jaikishan I, Rajendrakumar P, Ramesha MS, Viraktamath BC, Balachandran SM, Neeraja CN, Sujatha K, Srinivasa RK, Natarajkumar P, Hari Y, Sakthivel K, Ramaprasad AS, Sundaram RM (2010) Prediction of heterosis for grain yield in rice using 'key' informative EST-SSR markers. Plant Breed 129:108-111

Jaiswal P, Ni J, Yap I, Ware D, Spooner W, Youens CK, Ren L, Liang CZ, Zhao W, Ratnapu K, Faga B, Canaran P, Fogleman M, Hebbard C, Avraham S, Schmidt S, Casstevens TM, Buckler E, Stein L, McCouch SR (2006) Gramene: a bird's eye view of cereal genomes. Nucleic Acids Res 34:717-723

Joshi SP, Bhave SG, Chowdari KV, Apte GS, Dhonukshe BL, Lalitha K, Ranjekar PK, Gupta VS (2001) Use of DNA markers in prediction of hybrid performance and heterosis for a three-line hybrid system in rice. Biochem Genet 39:179-200 
Li YC, Rutger JN (2007) Registration of two tetraploid rice genetic stocks. J Plant Regist 1:173-174

Liu R, Qian W, Meng J (2002) Association of RFLP markers and biomass heterosis in trigenomic hybrids of oilseed rape (Brassica napus $\times$ B. campestris). Theor Appl Genet 105:1050-1057

Luan L, Wang X, Long WB, Liu YH, Tu SB, Zhao ZP, Kong FL, Yu MQ (2008) Microsatellite analysis of genetic variation and population genetic differentiation in autotetraploid and diploid rice. Biochem Genet 46:248-266

Marhold K, Lihová J (2006) Polyploidy, hybridization and reticulate evolution: lessons from the Brassicaceae. Plant Syst Evol 259:143-174

Martin JM, Talbert LE, Lanning SP, Blake NK (1995) Hybrid performance in wheat as related to parental diversity. Crop Sci 35:104-108

Masterson J (1994) Stomatal size in fossil plants: Evidence for polyploidy in majority of angiosperms. Science 264:421-424

McCouch SR, Teytelman L, Xu YB, Lobos KB, Clare K, Walton M, Fu BY, Maghirang R, Li ZK, Xing YZ, Zhang QF, Kono I, Yano M, Fjellstrom R, DeClerck G, Schneider D, Cartinhour S, Ware D, Stein L (2002) Development and mapping of 2240 new SSR markers for rice (Oryza sativa L.). DNA Res 9:199-207

Nei M (1978) Estimation of average heterozygosity and genetic distance from a small number of individuals. Genetics 89:583-590

Rohlf F (2002) NTSYS-pc. Numerical taxonomy and multivariate analysis system, Version 210th edn. Exeter Software, New York

Schut JW, Oi X, Stam P (1997) Association between relationship measures based on AFLP markers, pedigree data and morphological traits in barley. Theor Appl Genet 95:1161-1168

Shah SM, Naveed SA, Arif M (2013) Genetic diversity in basmati and non-basmati rice varieties based on microsatellite markers. Pak J Bot 45:423-431

Shahid MQ, Sun JF, Wei CM, Zhang P, Liu XD (2010) Studies on the abnormality of embryo sac and pollen fertility in autotetraploid rice during different growing seasons. Pak J Bot 42:7-19

Shahid MQ, Liu GF, Li JQ, Naeem M, Liu XD (2011) Heterosis and gene action study of agronomic traits in diploid and autotetraploid rice. Acta Agr Scand B-S P 61:23-32

Shahid MQ, Xu HM, Lin SQ, Chen ZX, Naeem M, Li YJ, Liu XD (2012) Genetic analysis and hybrid vigor study of grain yield and other quantitative traits in autotetraploid rice. Pak J Bot 44:237-246

Smith OS, Smith JSC, Bowen SL, Tenborg RA, Wall SJ (1990) Similarities among a group of elite maize inbreds as measured by pedigree, $F_{1}$ grain yield, grain yield, heterosis, and RFLPs. Theor Appl Genet 80:833-840

Song WC, Zhang YH (1992) Rice tetraploidy and its effect on agronomic traits and nutritional constituents. Acta Agron Sin 2:137-144

Tamura K, Dudley J, Nei M, Kumar S (2007) MEGA4: Molecular evolutionary genetics analysis (MEGA) software version 4.0. Mol Biol Evol 24:1596-1599

Tu SB, Luan L, Liu YH, Long WB, Kong FL, He T, Xu QF, Yan WG, Yu MQ (2007) Production and heterosis analysis of rice autotetraploid hybrids. Crop Sci 47:2356-2363

Wang MM, Zhu ZF, Tan LB, Liu FX, Fu YC, Sun CQ, Cai HW (2013) Complexity of indica-japonica varietal differentiation in Bangladesh rice landraces revealed by microsatellite markers. Breed Sci 63:227-232

Xangsayasane P, Xie FM, Hernandez JE, Boirromeo TH (2010) Hybrid rice heterosis and genetic diversity of IRRI and Lao rice. Field Crops Res 117:18-23

Xiao J, Li J, Yuan L, Tanksley SD (1995) Dominance is the major genetic basis of heterosis in rice as revealed by QTL analysis using molecular markers. Genetics 140:745-754

Xiao J, Li J, Yuan L, McCouch SR, Tanksley SD (1996) Genetic diversity and its relationship to hybrid performance and heterosis in rice as revealed by PCR-based markers. Theor Appl Genet 92:637-643

Yang YX, Wu JW, Chen ZX, Wang L, Li JQ, Liu XD, Lu YG (2009) Mining rice new germplasm containing $S_{5}^{n}$ gene by functional molecular marker and sequencing. Chinese Sci Bull 54:2212-2218

Yeh FC, Yang RC, Boyle TBJ, Ye ZH, Mao JX (1997) PopGene, the user-friendly shareware for population genetic analysis, molecular biology and biotechnology center. University of Alberta, Canada

Yu CY, Hu SW, Zhao HX, Guo AG, Sun GL (2005) Genetic distances revealed by morphological characters, isozymes, proteins and RAPD markers and their relationships with hybrid performance in oilseed rape (Brassica napus $L$ ). Theor Appl Genet 110:511-518

Yuan LP (1987) Breeding strategies for hybrid rice breeding. Hybrid Rice 1:1-3

Zha RM, Ling YH, Yang ZL, Zhao FM, Zhong BQ, Xie R, Sang XC, He GH (2008) Prediction of hybrid grain yield performances in Indica rice (Oryza sativa L.) with effect-increasing loci. Mol Breed 22:467-476
Zhang QF, Gao YJ, Yang SH, Ragab RA, Saghai Maroof MA, Li ZB (1994) A diallel analysis of heterosis in elite hybrid rice based on RFLPs and microsatellites. Theor Appl Genet 89:185-192

Zhang XQ, Wang XD, Jiang PD, Hua SJ, Zhang HP, Dutt Y (2007) Relationship between molecular marker heterozygosity and hybrid performance in intra- and interspecific hybrids of cotton. Plant Breed 126:385-391

Zhao MF, Li XH, Yang JB, Xu CG, Hu RY, Liu DJ, Zhang QF (1999) Relationship between molecular marker heterozygosity and hybrid performance in intra- and inter-subspecific crosses of rice. Plant Breed 118:139-144

\section{doi:10.1186/2193-1801-2-439}

Cite this article as: Wu et al:: Analysis on genetic diversification and

heterosis in autotetraploid rice. SpringerPlus 2013 2:439.

\section{Submit your manuscript to a SpringerOpen ${ }^{\circ}$ journal and benefit from:}

- Convenient online submission

- Rigorous peer review

- Immediate publication on acceptance

- Open access: articles freely available online

- High visibility within the field

- Retaining the copyright to your article

Submit your next manuscript at $>$ springeropen.com 